\title{
A SYBR Green real-time PCR assay to detect and quantify pork meat in processed poultry meat products
}

\author{
Sónia Soares a , Joana S. Amaral a,b, M. Beatriz P.P. Oliveira a , Isabel Mafra a,* \\ a REQUIMTE, Departamento de Ciências Químicas, Faculdade de Farmácia, Universidade do Porto, Rua de Jorge Viterbo Ferreira, 228, 4050-313, Portugal

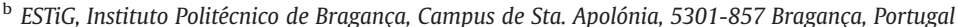

\section{A R T I C L E I N F O}

Article history:

Received 7 August 2012

Received in revised form 16 November 2012 Accepted 17 December 2012

\section{Keywords:}

Quantitative real-time PCR

SYBR Green

Authentication

Species identification

Pork meat

Poultry meat

\begin{abstract}
A B S T R A C T
Species identification in meat products has grown in interest in recent years since these foodstuffs are susceptible targets for fraudulent labelling. In this work, a real-time PCR approach based on SYBR Green dye was proposed for the quantitative detection of pork meat in processed meat products. For the development of the method, binary meat mixtures containing known amounts of pork meat in poultry meat were used to obtain a normalised calibration model from 0.1 to $25 \%$ with high linear correlation and PCR efficiency. The method revealed high specificity by melting curve analysis, being successfully validated through its application to blind meat mixtures, which confirmed its adequacy for pork meat determination. The fully applicability of the method was further demonstrated in commercial meat products, allowing verification of labelling compliance and identification of meat species in processed foods.
\end{abstract}

(c) 2013 Elsevier Ltd. All rights reserved.

\section{Introduction}

Species identification is a major concern due to the increased awareness of consumers regarding the composition of foods and the need to verify labelling statements. Processed meat products are susceptible targets for fraudulent labelling due to the economic profit that results from selling cheaper meats as partial or total replacement for high-valued meats. Lower amounts of meat than declared on the label and the substitution of muscle protein by cheaper vegetable protein are also common concerns in meat products (Ballin, 2011; Kesmen, Gulluce, Sahin, \& Yetim, 2009). In the case of pork, food manufacturers may choose to use porcine derivatives because they are cheap and readily available (Aida, Man, Wong, Raha, \& Son, 2005). Porcine derivatives used include pork fat (lard), mechanically recovered meats and porcine blood plasma (Nakyinsige, Man, \& Sazili, 2012). These practices are of concern for reasons such as: (i) economic, since it leads to unfair competition among producers; (ii) religious, since the consumption of certain species is not allowed in some religions; (iii) ethical, reflecting lifestyles such as vegetarianism; and (iv) health concerns.

The increasing demand for transparency in the meat industry and the enforcement of proper labelling have provided a driving force for the development of suitable analytical methodologies for meat species

\footnotetext{
* Correspondence to: I. Mafra, REQUIMTE, Departamento de Ciências Químicas, Faculdade de Farmácia, Universidade do Porto, Rua de Jorge Viterbo Ferreira, 228, 4050-313, Portugal. Tel.: + 351220428640.

E-mail addresses: jamaral@ipb.pt (J.S. Amaral), isabel.mafra@ff.up.pt (I. Mafra).
}

identification. Methods based either on protein or DNA analyses have been suggested. Protein based techniques, including electrophoretic, chromatographic (Toorop, Murch, \& Ball, 1997) and immunological (Asensio, González, García, \& Martín, 2008; Hajmeer, Cliver, \& Provost, 2003; Macedo-Silva et al., 2000) techniques, have some advantages when applied to raw meats, such as high sensitivity and sample throughput (Martín et al., 2009), but they are limited when applied to species identification in cured and highly processed meats, since proteins can be denatured during thermal, high pressures and other processing technologies. The ability of DNA molecules to withstand heat and pressure processing, when compared to proteins, and their ubiquity in every type of cell have led to DNA analysis for species identification in processed foods (Mafra, Ferreira, \& Oliveira, 2008). Analysis of DNA coupled with polymerase chain reaction (PCR) is considered to be fast, sensitive and highly specific for species identification in processed meat products. Studies have reported the application of PCR techniques for the qualitative detection of pork by species-specific primers or the analysis of restriction fragment length polymorphisms (PCR-RFLP) (Aida et al., 2005; Alaraidh, 2008; Che Man, Aida, Raha, \& Son, 2007; Haunshi et al., 2009; Kesmen, Sahin, \& Yetim, 2007; Matsunaga et al., 1999; Montiel-Sosa et al., 2000; Murugaiah et al., 2009; Soares, Amaral, Mafra, \& Oliveira, 2010). Although species-specific PCR based on duplex amplification can be used as a semi-quantitative approach to estimate animal species in meat products (Soares et al., 2010) or dairy products (Mafra, Ferreira, Faria, \& Oliveira, 2004; Mafra, Roxo, Ferreira, \& Oliveira, 2007), the use of a real-time PCR approach is recommended for more accurate quantitative information and to increase specificity. The simplest, least expensive and most direct fluorescent system adapted 